\title{
Estimating Heterotrophic Bacterial Productivity by Inorganic Radiocarbon Uptake: Importance of Establishing Time Courses of Uptake
}

\author{
W. K. W. Li \\ Marine Ecology Laboratory, Bedford Institute of Oceanography, Dartmouth, Nova Scotia, Canada B2Y 4A2
}

\begin{abstract}
Invariant proportionality between rate of anaplerotic inorganic carbon uptake and rate of heterotrophic bacterial carbon increase is assumed in the 'Romanenko technique' Measurements of short-term (min) $\mathrm{HCO}_{3}$ uptake rates by pseudomonas perfectomarinus, sampled from steady-state continuous cultures, indicate that this assumption is not valid. The use of short incubations in characterizing in situ rates was necessary because of non-linearity in the time-varying cellular radioactivity curves. Cells removed from cultures having a low dilution rate accumulated ${ }^{14} \mathrm{C}$ at progressively diminishing rates while those from cultures having a high dilution rate progressed at increasing rates. Such time-varying radioactivity curves are qualitatively consistent with compartmental analyses of systems in which, respectively, the pool of traced substances remains constant in size and expands. Sequential measurements of culture turbidity in the incubation vessel were consistent with these interpretations: there was no change in turbidity for a low dilution rate culture, whereas turbidity increased for a high dilution rate culture. It is suggested that natural plankton samples may likewise exhibit different growth responses when removed from the environment and enclosed in bottles. Time-varying radioactivity curves may prove useful in diagnosing growth.
\end{abstract}

\section{INTRODUCTION}

Romanenko et al. (1972) suggested that the rate of heterotrophic bacterial carbon increase $(P)$ could be estimated by assuming $\mathrm{CO}_{2}$ uptake to proceed at a rate (e) strictly proportional to the former rate. The apparent ease of conducting inorganic radiocarbon tracer incubation experiments without requiring independent estimates of biomass renders this method of heterotrophic productivity estimation appealing to aquatic microbiologists. However, there is as yet no rigorous examination of the assumption regarding invariant proportionality of rates.

Results presented in this paper indicate that for the marine bacterium Pseudomonas perfectomarinus, the rate proportionality does not remain constant as growth rate varies.

Define $R$, the dimensionless ratio of $\varrho$ to $P$,

$$
R=\varrho P^{-1},
$$

where

$$
P=\mu C
$$

$C=$ total cellular carbon content of the heterotrophic bacteria $\left(\mathrm{ML}^{-3}\right) ; \mu=$ specific growth rate $\left(\mathrm{T}^{-1}\right) ; P=$ bacterial carbon productivity $\left(\mathrm{ML}^{-3} \mathrm{~T}^{-1}\right) ; \varrho=$ rate of $\mathrm{CO}_{2}$ uptake $\left(M L^{-3} T^{-1}\right)$. The above equations may be combined to give

$$
R=\varrho \mu^{-1} C^{-1}
$$

Many investigations concerning the contribution of inorganic carbon to the total carbon requirement of heterotrophic microbes emphasize considerations based on mass rather than rate. Usually (e.g. Liener and Buchanan, 1951; Jones et al., 1958; Romanenko, 1964; Overbeck and Daley, 1973; Overbeck, 1979a), cells are exposed to ${ }^{14} \mathrm{CO}_{2}$ (or $\mathrm{H}^{14} \mathrm{CO}_{3}$ ) and after several hours or even days, measurements are made of the amount of ${ }^{14} \mathrm{CO}_{2}$ taken up by the cells and of the total cellular carbon content $(C)$. The amount of ${ }^{12} \mathrm{CO}_{2}$ taken up $\left(C_{a^{\prime}} M L^{-3}\right)$ is then calculated as the quotient of ${ }^{14} \mathrm{CO}_{2}$ taken up and the specific radioactivity of inorganic carbon in the suspending medium. The ratio $C_{a}$ $\mathrm{C}^{-1}$ is taken as the fractional contribution of $\mathrm{CO}_{2}$ to the total carbon requirement of the heterotrophic cells.

This approach which is based on considerations of mass is not entirely suitable for ecological studies because of the long incubation times. For example, 
Romanenko et al. (1972) recommend at least a $24 \mathrm{~h}$ incubation. Ideally, we wish to characterize in situ activity so that it is necessary to minimize changes in $\varrho$ and $P$ once the natural sample is enclosed in the incubation vessel (Overbeck, 1979b). The approach I used to determine $R$ (Equation 3 ) is based on measurements of rates. Short-term ( $\mathrm{min}$ ) $\mathrm{HCO}_{3}$ uptake rates (Q) were determined for bacteria sampled from steadystate continuous cultures where the specific growth rate $(\mu)$ was experimentally imposed and where the cellular carbon (C) was independently measured.

\section{MATERIALS AND METHODS}

Stock cultures of Pseudomonas perfectomarinus Zobell and Upham (ATCC 14405) were kept on slants of marine agar 2216 (Difco). Cells used to inoculate continuous cultures were batch grown in liquid medium of the same composition as was dispensed into the continuous cultures (Bacto-peptone: $0.20 \mathrm{~g}$, yeast extract: $0.04 \mathrm{~g}$, standard ocean water [Morel et al., 1979, omitting NaF]: $750 \mathrm{ml}$, 'Super-Q' water [Millipore] $250 \mathrm{ml}$ ).

A bank of six $200 \mathrm{ml}$ continuous cultures was operated simultaneously in parallel. Culture temperature was kept at $25^{\circ} \mathrm{C}$ by circulating water from a constant temperature bath through glass jackets surrounding each culture unit. Mixing was accomplished by the combination of aeration and circular magnetic spinner ('Star Head', Sybron). Air from an aquarium-type pump was first passed through activated carbon and cotton wool filters, and then through $0.1 \mathrm{~N} \mathrm{H}_{3} \mathrm{PO}_{4}$ before injection to the bottom of the culture vessels. The flow rate of injected air was maintained at $0.25 \mathrm{scfh}$ by rotameters (Matheson). Medium was dispensed to the cultures by a continuously variable speed peristaltic pump (Harvard 1203) equipped with a multiple tube adapter (Harvard 1220). Different flow rates were established by using silicone tubing (New Brunswick Scientific) of different diameters. The continuous culture system was constructed such that individual components could be autoclaved and reassembled aseptically. Culture turbidity was monitored by measurements of optical density at $650 \mathrm{~nm}$ using a Bausch and Lomb Spectronic 710 spectrophotometer. When cultures reached steady state, as assessed by relative constancy of $\mathrm{OD}_{650}$ over time, the specific growth rate ( $\mu$ ) was taken to be equal to the culture dilution rate (rate of flow per unit volume of culture)

Experiments to determine the time course of $\mathrm{HCO}_{3}$ uptake by steady-state cultures were performed on aliquots of culture removed from the growth vessels and incubated in autoclaved $120 \mathrm{ml}$ water-jacketed $\left(25^{\circ} \mathrm{C}\right)$ glass vessels. The samples were continuously mixed by magnetic stirring. Samples of culture received a small volume of $\mathrm{NaH}^{14} \mathrm{CO}_{3}$ solution (New England Nuclear) that had been freshly filtered through Millipore $0.45-\mu \mathrm{m}$ membrane. Final specific activity was about $1 \mu \mathrm{Ci} \mu \mathrm{mol}^{-1}$ the actual activity being determined in triplicate by radioassay of $50 \mu \mathrm{l}$ aliquots pipetted into scintillation vials containing $1.0 \mathrm{ml}$ water and $0.3 \mathrm{ml}$ phenethylamine followed by $10 \mathrm{ml}$ of Aquasol-2 (New England Nuclear). Samples were removed periodically from the incubation vessels by sterile syringe through a rubber septum in the rubber stopper sealing the vessel. Radiolabelled cells were immediately filtered onto a Millipore membrane $\{0.45 \mu \mathrm{m}\rangle$ and washed twice with $5 \mathrm{ml}$ aliquots of $2.6 \%$ $\mathrm{NaCl}$ solution followed by a further wash of the filter edge after the filtering tower had been removed. The filter was removed to a scintillation vial and dissolved in $1 \mathrm{ml}$ of 2-ethoxy-ethanol 1 and radioactivity assayed in $10 \mathrm{ml}$ Aquasol-2 (Kobayashi, 1980). Liquid scintillation counting was performed on a Beckman LS-3133 T spectrometer and quench correction was by the external standards ratio method. Total cell carbon was analyzed using a Perkin-Elmer Model $240 \mathrm{~B}$ elemental analyzer.

\section{RESULTS}

Out of nine incubations with cultures of varying $\mu, 3$ types of time-varying radioactivity curves were obtained which appeared to be related to the magnitude of $\mu$ (Fig. 1). For cells removed from cultures having low $\mu$ (e.g. $0.074 \mathrm{~h}^{-1}$ ), the instantaneous rate of ${ }^{14} \mathrm{C}$ accumulation decreased with time; for those from an intermediate $\mu$ (e.g. $0.115 \mathrm{~h}^{-1}$ ), the rate of ${ }^{14} \mathrm{C}$ accumulation appeared not to change over $3 \mathrm{~h}$; for those from a high $\mu$ (e.g. $0.181 \mathrm{~h}^{-1}$ ), the instantaneous rate of ${ }^{14} \mathrm{C}$ accumulation increased with time.

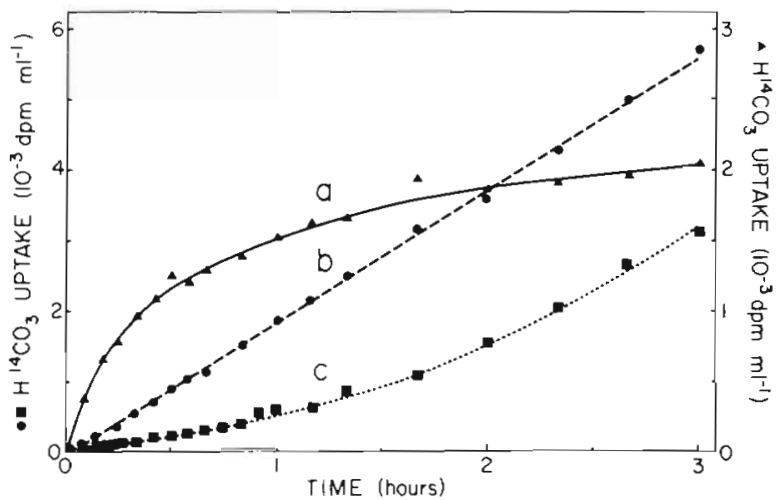

Fig. 1 Pseudomonas perfectomarinus. Time course of $\mathrm{H}^{14} \mathrm{CO}_{3}$ uptake by cells removed from steady-state continuous cultures of dilution rate $\mu$. (a) $\mu=0.074 \mathrm{~h}^{-1}$; (b) $0.115 \mathrm{~h}^{-1}$; (c) $0.181 \mathrm{~h}^{-1}$ 
In 2 experiments, incubations were extended to 6 or $7 \mathrm{~h}$ and $1 \mathrm{ml}$ aliquots were periodically sampled for measurement of culture turbidity. For cells removed from a culture of $\mu=0.044 \mathrm{~h}^{-1}$, the same pattern of time-varying radioactivity was observed as for other cultures having $\mu<0.115 \mathrm{~h}^{-1}$ (Fig. 2). There was no apparent change in $\mathrm{OD}_{650}$ in the incubation vessel over 6 hours (Fig. 2). For cells removed from a culture of $\mu=$ $0.139 \mathrm{~h}^{-1}$, the same pattern of time-varying radioactiv-

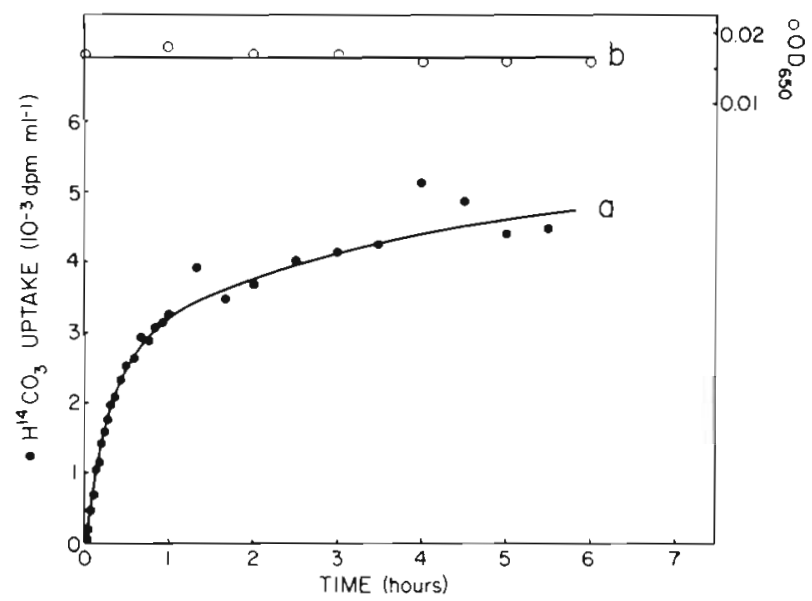

Fig. 2. Pseudomonas perfectomarinus. (a) Time course of $\mathrm{H}^{14} \mathrm{CO}_{3}$ uptake by cells removed from steady-state continuous culture: $\mu=0.044 \mathrm{~h}^{-1}$; (b) culture turbidity monitored in the incubation vessel from measurements of optical density at $650 \mathrm{~nm}$

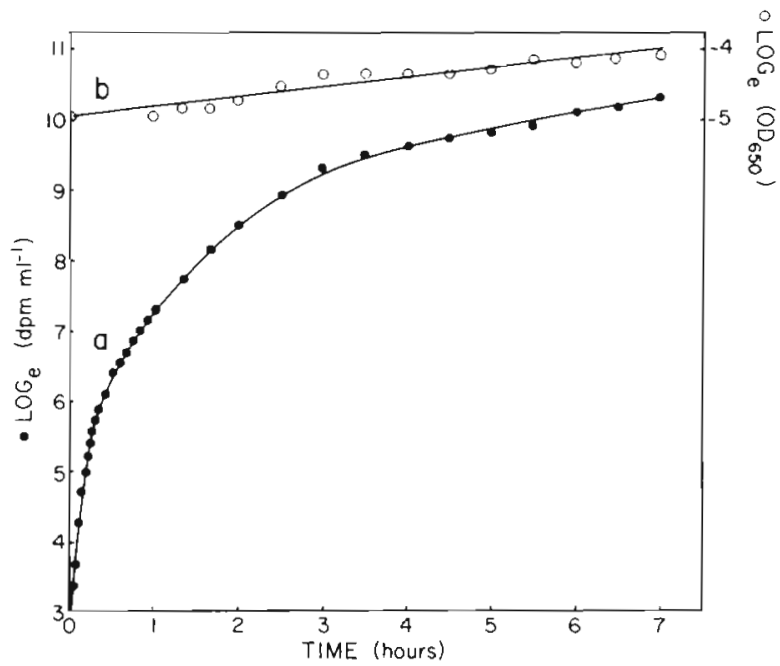

Fig. 3. Pseudomonas perfectomarinus. (a) Time course of $\mathrm{H}^{14} \mathrm{CO}_{3}$ uptake by cells removed from steady-state continuous culture: $\mu=0.139 \mathrm{~h}^{-1}$; (b) culture turbidity monitored in the incubation vessel from measurements of optical density at $650 \mathrm{~nm}$. Note logarithmic scales for both ordinates

ity was observed as for other cultures having $\mu>0.115$ $\mathrm{h}^{-1}$ (Fig. 3). Note that the natural logarithms, rather than absolute values, of $\mathrm{H}^{14} \mathrm{CO}_{3}$ uptake are plotted on the ordinate in this case. There was a highly significant $(\mathrm{P}<0.001)$ increase in $\log _{\mathrm{e}} \mathrm{OD}_{650}$ over $7 \mathrm{~h}$ (Fig. 3). Linear regression of $\log _{e} \mathrm{OD}_{650}$ on time yielded a specific growth rate of $0.138 \mathrm{~h}^{-1}$ with a $95 \%$ confidence interval of $0.027 \mathrm{~h}^{-1}$. This value is not statistically different from the dilution rate of the continuous culture from which the cells were transferred.

Initial rates of inorganic carbon uptake (O) were calculated from the slopes of the linear regression of cellular ${ }^{14} \mathrm{C}$ on time during the first $15 \mathrm{~min}$ of incubation. Values of $R$ were calculated according to Equa-

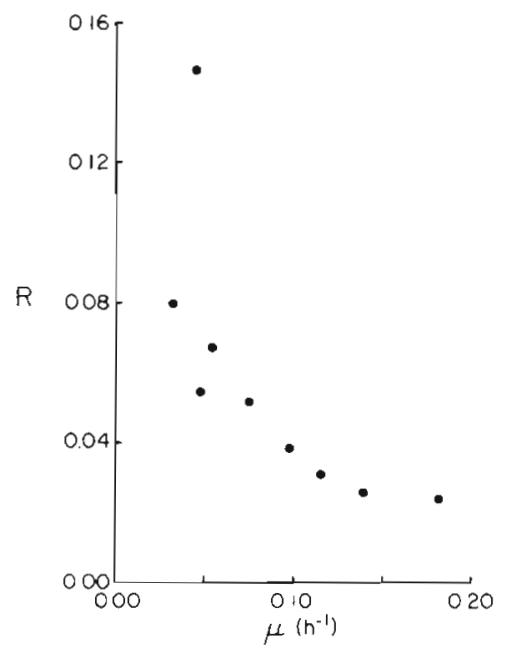

Fig. 4. Pseudomonas perfectomarinus. Variation of the ratio (R) of bicarbonate uptake rate to total carbon productivity as a function of culture dilution rate $(\mu)$

tion 3. Fig. 4 shows $R$ decreasing as a function of $\mu$ from about $8 \%$ to $2 \%$ over the range of $\mu$ from $0.032 \mathrm{~h}^{-1}$ to $0.181 \mathrm{~h}^{-1}$. An $R$ value of $15 \%$ measured at $\mu=0.044$ $\mathrm{h}^{-1}$ appears not to follow the trend line established by the other points. The reason for this is not apparent.

\section{DISCUSSION}

\section{Time Course of $\mathrm{H}^{14} \mathrm{CO}_{3}$ Uptake}

The process of removing cells growing at a steadystate rate of $\mu$ in continuous culture and transferring them to an incubation vessel is equivalent to a stepdown' transition in culture dilution rate. In effect, there is a rapid change in conditions from those which impose a positive growth rate (i.e. $\mu$ ) to those which impose a growth rate of zero. Whether or not an immediate adjustment in culture growth rate is expected in such step-down transitions is not absolutely clear. Evidently, predictions regarding dynamic transitions based on steady state or equilibrium models (e.g. Monod model) are not necessarily accurate (Per- 
ret, 1960; Young et al., 1970; Harrison and Topiwala, 1974; Burmaster, 1979). The reason for this is that when environmental conditions are changed, the various mechanisms concerned with cell growth and division respond at different rates and in a sequential manner. The question remains whether or not transient culture growth rates are experimentally observable during the finite time required for physiological adjustment.

There is evidence based on step-up transition experiments that growth rate accommodates immediately to small changes in dilution rate, however, the time required for growth rate to equal dilution rate increases with larger changes in dilution rate (Mateles et al., 1965; Harrison and Wren, cited in Harrison and Topiwala, 1974). An analogous situation was observed in the present study: whether or not culture growth continued after step-down to zero dilution rate appeared to be related to the dilution rate immediately prior to transition (Figs. 2, 3).

These patterns of growth rate responses were anticipated by Perret (1960) who described deviations from the Monod model in terms of 'growth rate hysteresis'. He postulated that if the rate of change away from steady state were slight, there should be no significant lag in growth rate response. On the other hand, if the rate of change were large, 'the concentration of components within the system will not have time to reach their exponential state levels'. The transient growth rate would then be expected to be less than the final steady-state rate during step-up transitions and be greater during step-down transitions.

It has since been suggested (Harrison and Topiwala, 1974) that a slight increase in dilution rate brings rapid adjustment because of 'extra' RNA (Koch, 1970, 1971) already present whereas a large increase necessitates new RNA synthesis. Conversely, it might be that a large decrease in dilution rate necessitates substantial RNA degradation (and therefore growth rate hysteresis) whereas a slight decrease brings rapid adjustment because 'extra' RNA is retained. Growth rate control mechanisms must therefore be quite sensitive to slight changes in the environment.

A time-varying radioactivity plot which asymptotically tends towards a plateau is consistent with expectations from compartmental analyses of systems for which the pool size of the traced substance remains constant (Sheppard, 1962; Atkins, 1969; Bernhard et al., 1975). The observation of time invariant $\mathrm{OD}_{650}$ after step-down transition of a low dilution rate culture (Fig. 2) is consistent with this. Conversely, a time-varying radioactivity plot which curves upwards, if a linear scale is used on the ordinate, is consistent with an expansion of the pool being traced. The increase in $O D_{650}$ after step-down transition of a high dilution rate culture (Fig. 3) is consistent with this. A linear time course of $\mathrm{H}^{14} \mathrm{CO}_{3}$ uptake (Fig, 1) presumably represents a situation intermediate to the above 2 cases.

In the first case, the radioactivity curve simply reflects the asymptotic approach of specific activity towards isotopic equilibrium when there is no net growth of the pool being radiolabelled. In the second case, there is also an approach to isotopic equilibrium. However, since there is exponential growth of the labelled pool, radioactivity does not attain a plateau. Instead, radioactivity tends towards a specific increase rate matching that of the pool being labelled (cf. Taylor and Jannasch, 1976). Diagramatically, isotopic equilibrium is achieved during balanced exponential growth when plots of $\log _{e}\left(O D_{650}\right)$ vs. $t$ and $\log _{e}(\mathrm{dpm}$ $\mathrm{ml}^{-1}$ ) vs. $t$ yield indistinguishable slopes. Linear regression of $\log _{e}\left(\mathrm{dpm} \mathrm{ml} \mathrm{pl}^{-1}\right)$ vs. $t$ for $t$ between 3.5 and $7.0 \mathrm{~h}$ for the data in Fig. 3 gives a slope of 0.227 $\mathrm{h}^{-1} \pm 0.017 \mathrm{~h}^{-1}$. It is not surprising that the specific rate of radioactivity increase from 3.5 to $7.0 \mathrm{~h}$ was significantly greater than the specific rate of biomass increase $\left(0.138 \mathrm{~h}^{-1} \pm 0.027 \mathrm{~h}^{-1}\right)$ since uniform labelling would not be expected during this time for the culture whose doubling time was $5 \mathrm{~h}$.

\section{Ratio of Bicarbonate Uptake Rate to Productivity}

Based on $\varrho$ values calculated form the first 15 min of incubation, $R$ was found to decrease with increasing $\mu$ (Fig. 4). Previous studies investigating the contribution of inorganic carbon to total carbon requirement of heterotrophic microbes based on considerations of mass also indicate a varying ratio. Factors which have been shown to affect the ratio include whether cells are growing or not and the $\mathrm{CO}_{2}$ concentration (Liener and Buchanan, 1951), the nature of the substrates in the suspending medium (Romanenko, 1964; Sorokin, 1966; Oura et al., 1980), the concentration of such substrates (Overbeck, 1972, 1979a) and the age in batch culture (Overbeck and Daley, 1973; Overbeck, 1974,1979 a).

Results from a recent study on the anaplerotic metabolism of the fungus Aspergillus nidulans (Bushell and Bull, 1981) are relevant to this discussion of the relationship between $R$ and $\mu$. These authors measured the activities of anaplerotic carboxylases as a function of culture dilution rate. Although the activities of phosphoenolpyruvate carboxylase and pyruvate carboxylase were both dependent on dilution rate, they did not vary in the same manner. As markers for different pathways of $\mathrm{CO}_{2}$ fixation (Oura et al., 1980), the activities of these enzymes suggest that the relative importance of different anaplerotic sequences may also be dependent on dilution rate. Oura (1974) has calculated from theory that different percentages 
of $\mathrm{CO}_{2}$ contributions to total carbon result from different $\mathrm{CO}_{2}$-fixing mechanism.

\section{Implications for Ecological Studies}

The use of fixed end-point isotope measurements after long incubations ( $h$ ) to characterize in situ processes has already been amply discredited (Wiebe and Smith, 1977; Lancelot, 1979, Mague et al., 1980; Glibert and Goldman, 1981 Goldman et al., 1981a, b; Horrigan and McCarthy, 1981; Marra et al., 1981). The results from this study, and also those of Jordan and Peterson (1978) concerning $\left({ }^{35} \mathrm{~S}\right) \mathrm{SO}_{4}$ uptake by bacteria, make it clear that rates of substrate uptake may change very quickly once cells are removed from continuous cultures. It is possible that analogous effects occur when natural plankton samples are removed from the environment and enclosed in bottles. In this regard, the concavity of time-varying radioisotope curves (whether upwards or downwards) may prove useful as a qualitative diagnostic indicator. Deductions of mass flux from measurements of radioisotope flux ought to be based on a knowledge of whether or not the traced pool remains constant during incubations.

However, even given accurate estimates of in situ bicarbonate uptake rates by heterotrophic bacteria, the calculation of bacterial carbon production remains problematical because of the dependence of $\mathrm{R}$ upon $\mu$. Jordan and Likens (1980) found that their estimate of bacterial production in an oligotrophic lake using an $R$ value of $6 \%$ in the dark $\mathrm{CO}_{2}$ uptake method did not agree well with estimates using other methods. Although work by others has indicated that the contribution of inorganic carbon to total carbon requirement for heterotrophic microbes varies for different conditions (vide supra), results from this study point to a functional relationship between $R$ and $\mu$.

Acknowledgements. I thank Drs. T. Platt, J. Cullen and W. G. Harrison for reviewing the manuscript. I also thank Pat Lindley for carbon analyses and Linda Kenney for typing the manuscript.

\section{LITERATURE CITED}

Atkins, G. L. (1969). Multicompartment models for biological systems, Methuen and Co., London

Bernhard, M., Bruschi, A., Moler, F. (1975). Use of compartmental models in radioecological laboratory studies. In: Design of radiotracer experiments in marine biological systems. International Atomic Energy Agency, Vienna. Tech. Rep. Ser. 167: 241-275

Burmaster, D. E. (1979). The unsteady continuous culture of phosphate-limited Monochrysis lutheri Droop: experimental and theoretical analysis. J. exp. mar. Biol. Ecol. 39: $167-186$

Bushell, M. E., Bull, A. T. (1981). Anaplerotic metabolism of
Aspergillus nidulans and its effect on biomass synthesis in carbon limited chemostats. Arch. Microbiol. 128: 282-287

Glibert, P. M., Goldman, J. C. (1981). Rapid ammonium uptake by marine phytoplankton. Mar. Biol. Lett. 2: 25-31

Goldman, J. C., Dennett, M. R., Riley, C. B. (1981a). Marine phytoplankton photosynthesis and transient ammonium availability. Mar. Biol. Lett. 2; 323-331

Goldman, J. C., Taylor, C. D., Glibert, P. M. (1981b). Nonlinear time-course uptake of carbon and ammonium by marine phytoplankton. Mar Ecol. Prog. Ser. 6: 137-148

Harrison, D. E. F., Topiwala, H. H. (1974). Transient and oscillatory states of continuous culture. In: Ghose, T. K., Fiechter, A., Blackebrough, N. (eds.) Advances in biochemical engineering, Vol. 3. Springer, Berlin, pp. $167-219$

Horrigan, S. G., McCarthy, J. J. (1981). Urea uptake by phytoplankton at various stages of nutrient depletion. J. Plankton Res. 3: 403-414

Jones, G. E., Thomas, W. H., Haxo, F. T. (1958). Preliminary studies of bacterial growth in relation to dark and light fixation of $\mathrm{C}^{14} \mathrm{O}_{2}$ during productivity determinations. U.S. Fish and Wildlife Service, Washington. Special scientific report: fisheries 279: 79-86

Jordan, M. J., Likens, G. E. (1980). Measurement of planktonic bacterial production in an oligotrophic lake. Limnol. Oceanogr. 25: 719-732

Jordan, M. J., Peterson, B. J. (1978). Sulphate uptake as a measure of bacterial production. Limnol. Oceanogr. 23: $146-150$

Kobayashi, $Y$ (1980). Guide to counting various types of filters by LSC, LSC Applications Notes \#48, New England Nuclear

Koch, A. L. (1970). Overall controls on the biosynthesis of ribosome in growing bacteria. J. theor. Biol. 28: 203-231

Koch, A. L. (1971). The adaptive responses of Escherichia coli to a feast and famine existence. Adv. microb. Physiol. 6: $147-217$

Lancelot, C. (1979). Gross excretion rates of natural marine phytoplankton and heterotrophic uptake of excreted products in the Southern North Sea, as determined by shortterm kinetics. Mar. Ecol. Prog. Ser. 1: 179-186

Liener, I. E., Buchanan, D. L. (1951). The fixation of carbon dioxide by growing and nongrowing yeast. J. Bact. 61: $527-534$

Mague, T. H., Friberg, E., Hughes, D. J., Morris, I. (1980). Extracellular release of carbon by marine phytoplankton: a physiological approach. Limnol. Oceanogr. 25: 262-279

Marra, J., Landriau, G. Jr., Ducklow, H. W. (1981). Tracer kinetics and plankton rate processes in oligotrophic oceans. Mar. Biol. Lett. 2: 215-223

Mateles, R. I., Ryu, D. Y., Yasuda, T. (1965). Measurement of unsteady state growth rates of microorganisms. Nature, Lond. 208: 263-265

Morel, F. M. M., Rueter, J. G., Anderson, D. M., Guillard, R. R. L. (1979). Aquil: a chemically defined phytoplankton culture medium for trace metal studies. J. Phycol. 15: 135-141

Oura, E. (1974). Carbon dioxide fixation process in yeast, particularly baker's yeast; theoretical background. In: Klaushofer, H., Sleytr, U. B. (eds.) Proceedings of the 4th International Symposium on Yeasts, Vienna, Part II, pp. 53-60

Oura, E., Haarasilta, S., Londesborough, J. (1980). Carbon dioxide fixation by baker's yeast in a variety of growth conditions. J. gen. Microbiol. 118: 51-58

Overbeck, J. (1972). Experimentelle Untersuchungen zur Bestimmung der bakteriellen Produktion im See. Verh. int. Verein. theor. angew. Limnol. 18: 176-187 
Overbeck, J. (1974). Microbiology and biochemistry. Mitt. int. Verein. theor. angew. Limnol. 20: 198-228

Overbeck, J. (1979a). Dark $\mathrm{CO}_{2}$ uptake - biochemical background and its relevance to in situ bacterial production. Arch. Hydrobiol. Beih. Ergebn. Limnol. 12: 38-47

Overbeck, J. (1979b). Studies on heterotrophic functions and glucose metabolism of microplankton in plußsee. Arch. Hydrobiol. Beih. Ergebn. Limnol. 13: 56-76

Overbeck, J., Daley, R. J. (1973). Some precautionary comments on the Romanenko technique for estimating heterotrophic bacterial production. Bull. Ecol. Res. Comm. (Stockholm) 17: 342-344

Perret, C. J. (1960). A new kinetic model of a growing bacterial population. J. gen. Microbiol. 22: 589-617

Romanenko, V. I. (1964). Heterotrophic assimilation of $\mathrm{CO}_{2}$ by bacterial flora of water. Microbiology 33: 610-614

Romanenko, V. I., Overbeck, J., Sorokin, Y. I. (1972). Estimation of production of heterotrophic bacteria using ${ }^{14} \mathrm{C}$. In: Sorokin, Y. I., Kadota, H. (eds.) Techniques for the assessment of microbial production and decomposition in fresh waters. IBP Handbook No. 23, Blackwell, Oxford, pp 82-85

Sheppard, C. W. (1962). Basic principles of the tracer method Introduction to mathematical tracer kinetics, Wiley, New York

Sorokin, J. I. (1966). On the carbon dioxide uptake during the cell synthesis by microorganisms. Z. allg. Mikrobiol. 6 : $69-73$

Taylor, C. D., Jannasch, H. W. (1976). Subsampling techniques for measuring growth of bacterial cultures under high hydrostatic pressure. Appl. environ. Microbiol. 32: 355-359

Wiebe, W. J., Smith, D. F. (1977), Direct measurement of dissolved organic carbon release by phytoplankton and incorporation by microheterotrophs. Mar. Biol. 42: 213-223

Young, T. B., Bruley, D. F., Bungay, H. R., III (1970). A dynamic mathematical model of the chemostat. Biotechnol. Bioeng. 12: 747-769

This paper was presented by Dr. T. Platt; it was accepted for printing on January 13,1982 